\title{
DETERMINATION OF METAL IONS RELEASED BY STAINLESS STEEL ARCH BAR INTO BIO-FLUIDS
}

\author{
Lori A. Joseph ${ }^{1}$, Omoniyi K. Israel ${ }^{2 *}$, Ekanem J. Edet ${ }^{1}$ and Patricia A. Ekwumemgbo ${ }^{1}$ \\ ${ }^{1}$ Chemistry Department, Ahmadu Bello University, Zaria, Nigeria \\ ${ }^{2}$ Ahmadu Bello University, School of Basic and Remedial Studies, Funtua, Nigeria
}

(Received July 10, 2008; revised November 10, 2008)

\begin{abstract}
The amounts of cobalt, iron, manganese, nickel and chromium ions released from new and reused stainless steel arch bar used for maxillomandibular fixation was determined in Hank's solutions of different hydrogen and chloride ions concentrations, whole blood serum and phosphate buffered saline (PBS) in vitro, over a six-week immersion time at $37^{\circ} \mathrm{C}$, by atomic absorption spectrophotometry. The corrosion levels of the wires due to effects of media and incubation times in the bio-fluids were compared by Duncan's two-way ANOVA (P $<0.05)$. Pearson's correlation was used in establishing relationship in the amounts of metal ions released by new and reused arch bars. The study indicated that the reused wires released more ions than new ones at all time points. The variation of $\mathrm{pH}$ and chloride ions of the bio-fluids had a significant effect on the amount of $\mathrm{Ni}, \mathrm{Mn}$ and $\mathrm{Cr}$ ions released. Ageing prior use of arch bars significantly increased $\mathrm{Ni}$ ions released into the bio-fluids.
\end{abstract}

KEY WORDS: Maxillomandibular fixation, Corrosion, Arch bar, Bio-fluids, Metal ions

\section{INTRODUCTION}

Maxillomandibular fixation, MMF is the most commonly used treatment for mandible fractures. This process involves anchoring arch bars to the gums of the maxilla and the mandible. The arch bars are held in place by gauge wires, which are wrapped around the molars, the device is left for 4 to 6 weeks of the healing process [1]. Arch bars which had been used clinically by a patient can be retrieved and may be reused for several reasons, including cost [2].

Much of the focus on the long-term biocompatibility of metallic implants has centred on their tendency to undergo electrochemical corrosion while in contact with physiological fluids. The electrochemical reaction resulting to the release of metal ions is coupled with a corresponding reduction reaction of constituents in the aqueous environment to maintain charge neutrality [3]. The oral cavity is warm and damp, and during the ingestion of food, conditions of considerable acidity or mild alkalinity and ranges of temperature are experienced. Stainless steel (SS) contains chromium that oxidises at the surface to resist corrosive attack [4]. This metaloxide passive film spontaneously forms (passivation) and reforms (repassivation) in air and under most tissue fluid conditions; oxygen is necessary to form and maintain the film, whereas acidity and chloride ions can be particularly detrimental to it [5].

Despite the kinetic barriers to corrosion release of metal ions from SS brackets have been reported, with the major corrosion products being iron, chromium and nickel [6]. These ions have potential for producing allergic, toxic or carcinogenic reactions [7]. Tsui et al. [2] investigated the metal ions released from SS brackets immersed in buffers of $\mathrm{pH} 4$ and 7 . The recycled brackets released more ions than the new ones, reduction of the $\mathrm{pH}$ of artificial saliva resulted in the leaching of more metal ions with immersion time [2].

Wenyi et al. [8] measured the amount of nickel ions released from three types of nickelcontaining arch wires into synthetic saliva in vitro. It was inferred that the maximum amount of nickel released from all tested arch wires was 700 times lower than the concentrations necessary to elicit cytotoxic reactions in human peripheral blood mononuclear cells (PBMCs) [8]. Study

*Corresponding author. E-mail: israelflourish@yahoo.com 
by Angela et al. [9] showed that the ions released from metallic implants resulted in local immune dysfunction, inflammation and tissue cell death. Nickel(II) and vanadium(V) reduce cell viability and proliferation in a dose-dependent manner [9].

Pitting corrosion generally occurs in chloride or bromide solutions. It can be initiated at a fault in the passive layer or a surface defect. The steel underneath the defect dissolves leading to a building up of positively charged metal ions, which in turn causes negative charges (e.g. chloride ions) to migrate towards the defect. Even in a neutral solution, this can cause the $\mathrm{pH}$ to drop locally to 2 or 3 , thereby preventing the regeneration of the passive layer [10].

The study aimed to mimic the in vivo conditions of immersion in five bio-fluids, including the presence of factors such as ageing prior use of arch bars, $\mathrm{pH}$ and chloride ions variations of the bio-fluids and relate these conditions to the amount of metal ions released by arch bars with immersion time up to 6 weeks. This is to improve understanding of the biocompatibility profile of arch bars over the 6 weeks healing period in vivo.

\section{EXPERIMENTAL}

\section{Materials and methods}

A total of 150 Erich arch bars (Unitek, Monrovia, California, USA) cut into standard sized pieces $(6 \mathrm{~cm}$ length of average weight $750.5 \pm 8.0 \mathrm{mg})$ were used for the experiment. They were divided into new (as received from the manufacturer) and reused (retrieved and sterilised after 6 weeks of clinical use). Elemental composition of the arch bar (AISI 316 grade) was carried out by the dissolution of $0.2 \mathrm{~g}$ of the metallic sample in $3 \mathrm{~mL}$ of hot concentrated $\mathrm{HNO}_{3}$ and $10 \mathrm{~mL}$ of concentrated $\mathrm{HCl}$ solution. Analysis of metal ions in the diluted solution (with deionised water) using graphite furnace atomic absorption spectrophotometry (model TAS990, Intec Co. Ltd., Rome) gave: $60.05 \% \mathrm{Fe}, 18.35 \% \mathrm{Cr}, 18.62 \% \mathrm{Ni}, 2.94 \% \mathrm{Mn}$ and $0.03 \%$ Co [11].

\section{Bio-fluids for the study}

Whole blood serum, WBS, was obtained by collecting fresh bovine blood of a healthy male cow into slantly positioned boiling tubes. WBS obtained after about 3 hours had a pH of 7.68. Hank's solution (HS) - to simulate extra-cellular body fluids - was prepared according to the Table 1. The solution was adjusted to $\mathrm{pH} 4.0(\mathrm{HSpH} 4)$ and $\mathrm{pH} 7.0(\mathrm{HSpH} 7)$ with $0.5 \mathrm{M}$ $\mathrm{Na}_{2} \mathrm{HPO}_{4}$ and $0.5 \mathrm{M} \mathrm{NaH} \mathrm{PO}_{4}$ buffer solutions and drops of $1 \% \mathrm{HCl}$ solution. The concentration of $\mathrm{HS}$ with high chloride ions $(\mathrm{HSCl})$ was obtained by making the concentration of chloride ions in HS to be $1.63 \times 10^{-1}$ mol. $\mathrm{L}^{-1}$. Phosphate buffered saline, PBS solution manufactured by Nissui Pharmaceutical Co. Ltd., Tokyo, Japan had a pH of 7.45.

Table 1. Ion concentration of Hank's solution [14].

\begin{tabular}{|l|c|}
\hline Ion & Concentration $\left(\mathrm{molL}^{-1}\right)$ \\
\hline $\mathrm{Na}^{+}$ & $1.42 \times 10^{-1}$ \\
\hline $\mathrm{K}^{+}$ & $5.81 \times 10^{-3}$ \\
\hline $\mathrm{Mg}^{2+}$ & $8.11 \times 10^{-4}$ \\
\hline $\mathrm{Ca}^{2+}$ & $1.26 \times 10^{-3}$ \\
\hline $\mathrm{Cl}^{-}$ & $1.45 \times 10^{-1}$ \\
\hline $\mathrm{HPO}_{4}{ }^{2-}$ & $7.78 \times 10^{-4}$ \\
\hline $\mathrm{SO}_{4}{ }^{2-}$ & $8.11 \times 10^{-4}$ \\
\hline $\mathrm{CO}_{3}{ }^{2-}$ & $4.17 \times 10^{-3}$ \\
\hline
\end{tabular}


In vitro corrosion study

Each polypropylene bottle containing $20 \mathrm{~mL}$ of Hank's solution- HS at pH 4.0, pH 7.0 or HS with high chloride ion ( $\mathrm{HSCl}$ )- and a $6 \mathrm{~cm}$ length of new or reused arch bar was closed and then placed in an incubator at $37{ }^{\circ} \mathrm{C}$. Three independent samples were prepared for each experimental group. Following incubation at the end of the 1 day, 1, 2, 4 and 6 weeks, $10 \mathrm{~mL}$ of each of the experimental solutions were withdrawn with a syringe after shaking. These were then digested with $3 \mathrm{~mL}$ of concentrated $\mathrm{HNO}_{3}$ and $10 \mathrm{~mL}$ of concentrated $\mathrm{HCl}$ solution on a hot plate at 100 ${ }^{\circ} \mathrm{C}$. The digest was then made up to $20 \mathrm{~mL}$ with doubly distilled water. The digestion was repeated for each of the experimental solutions. The corrosion experiment was also carried out for WBS and PBS.

The concentration of $\mathrm{Co}, \mathrm{Fe}, \mathrm{Mn}, \mathrm{Ni}$ and $\mathrm{Cr}$ ions in the various bio-fluids was measured using graphite furnace atomic absorption spectrophotometry (model TAS990, Intec Co. Ltd., Rome, Italy). The concentrations of these ions in the bio-fluids alone were taken as control. The quality assurance for the analyses was conducted through the spiking method, and mean $\%$ recovery for the analyses ranged from $83.4 \pm 0.15$ to $95.5 \pm 0.30$.

\section{RESULTS AND DISCUSSION}

The results are expressed as the average of triplicate determinations \pm the standard deviation, as presented in Figure 1-5. Data was analysed using SAS (statistical soft ware), and a 2-way ANOVA applied using the Duncan's Post-hoc multiple range test (DMRT) at $\mathrm{P}<0.05$ to assess differences in the mean values of the metal ions released, due to effects of media and incubation time of the test materials in the bio-fluids. Pearson's correlation was used in establishing whether or not relationships exist in the amount of metal ions released by new and reused arch bars and the probability levels of significance at $\mathrm{P}<0.05$.

\section{Release of Co ions}

No cobalt ion was detected in the bio-fluids until at incubation time of 6 weeks for the new and reused wires. The highest level of $0.010 \pm 0.002 \mathrm{mg} / \mathrm{L}$ was recorded for the reused wire immersed in $\mathrm{HSCl}$ (Figure 1). The amount of Co ions released from the wires increased with decrease in $\mathrm{pH}$ of HS. The low level of Co ions released into the test solutions can be traced to its low elemental composition in the wire sample. Duncan's multiple range test (DMRT) showed a significant difference in the amount of Co ions released into PBS compared to the other media, but no statistically significant difference due to extended incubation time of the new arch bar in the various bio-fluids. Pearson's correlation depicted a positive relationship in the mean amount of Co ions released into the bio-fluids by new and reused arch wires ( $\mathrm{r}=$ 0.889 ), with no statistical level of significance. 


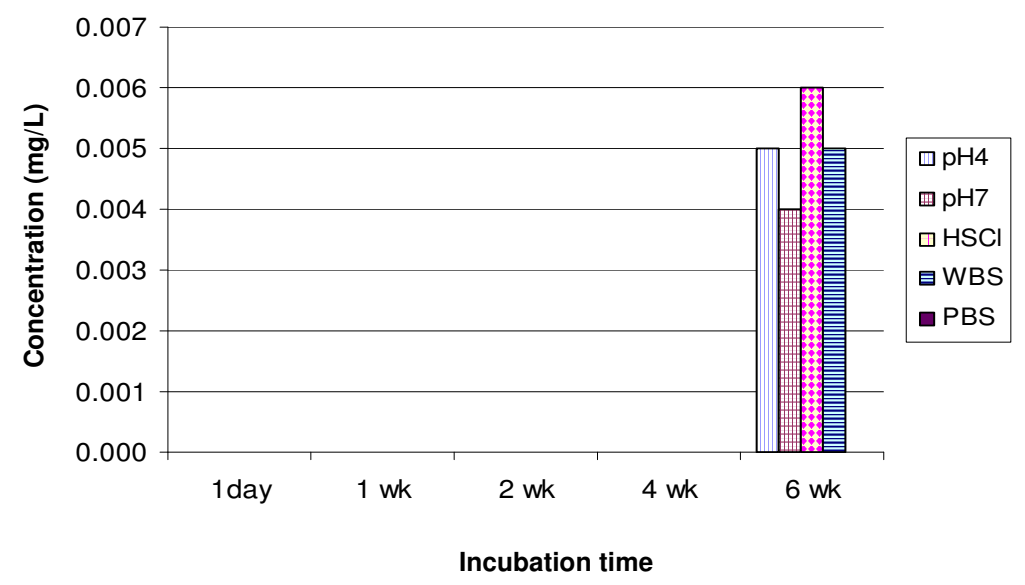

Figure 1a. Cobalt ions released by new arc bar into bio-fluids.

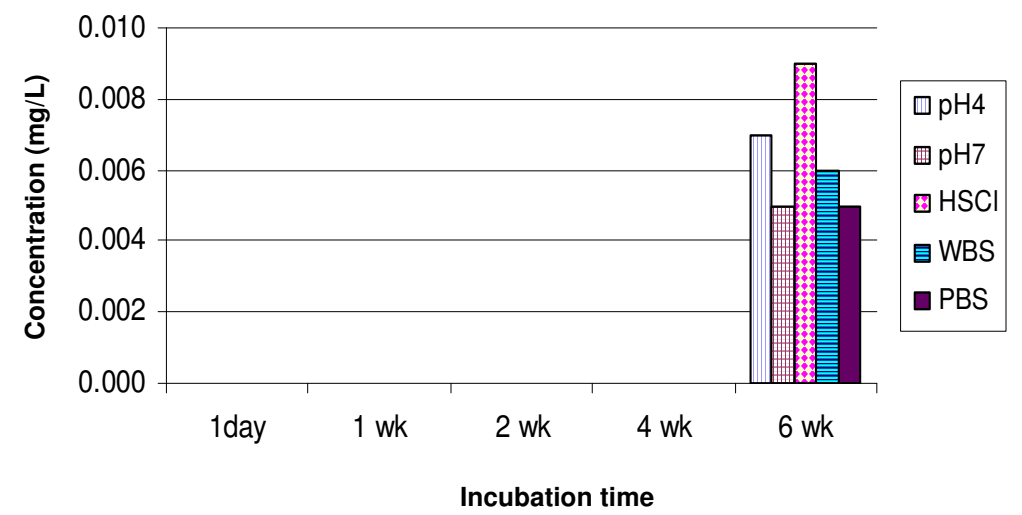

Figure 1b. Cobalt ions released by reused arc bar into bio-fluids.

\section{Release of Fe ions}

As illustrated in Figure 2, the lowest concentrations of dissolved Fe ions were measured in PBS, with no detectable amount after 1 day and a value of $0.020 \pm 0.002 \mathrm{mg} / \mathrm{L}$ after 6 weeks incubation of the new wires. The highest concentrations were measured in WBS and HSpH4 with values $0.005 \pm 0.001 \mathrm{mg} / \mathrm{L}$ after 1 day and $0.058 \pm 0.002 \mathrm{mg} / \mathrm{L}$ after 6 weeks incubation of the reused wires in HSCl. DMRT showed a significant difference in the amount of Fe ions released into $\mathrm{HSpH} 4$ compared to the other media, but increased incubation time did not result to significant release of Fe ions from the new arch bar into the bio-fluids. Pearson's correlation depicted a positive relationship in the mean amount of $\mathrm{Fe}$ ions released into the bio-fluids by new and reused arch wires $(r=0.821)$, with no statistical level of significance. The difference between the new and reused groups for Fe ions released was statistically significant after 4 and 6 weeks of incubation. 


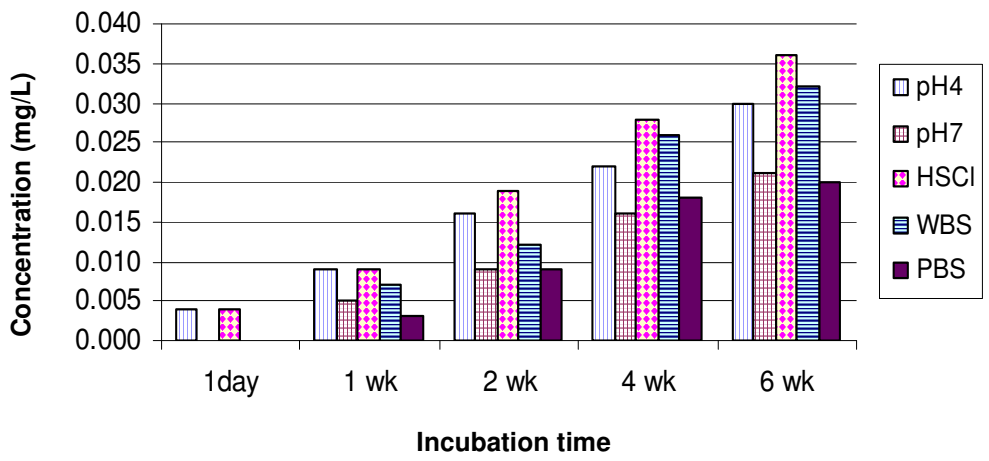

Figure 2a. Iron ions released by new arc bar into bio-fluids.

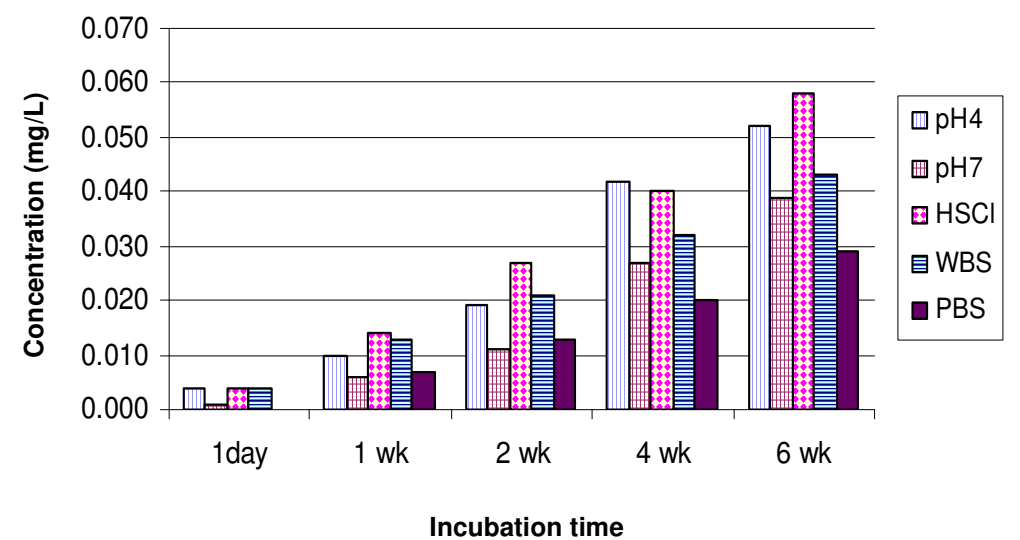

Figure $2 b$. Iron ions released by reused arc bar into bio-fluids.

\section{Release of Mn ions}

As shown in Figure 3, the release of Mn ions was not detectable until after 2 weeks of incubation of the new samples, with the reused samples releasing more Mn ions than the new ones. A sharp increase was obtained in the levels of Mn ions released between 2 and 4 weeks of incubation. The highest level of Mn ions released was recorded for the reused wire after 6 weeks incubation in WBS $(0.074 \pm 0.001 \mathrm{mg} / \mathrm{L})$. DMRT presented a slight significant difference in the amount of $\mathrm{Mn}$ ions released into the media by an increase in chloride ion concentration, while increasing the hydrogen ion concentration of the media resulted to a highly significant difference. Increased incubation time did not result to significant release of $\mathrm{Mn}$ ions from the new arch bar into the bio-fluids. There was no significant difference between the Mn ions released by the new and reused wires, a positive correlation was obtained with $r=0.911$. The ranking from mild to aggressive corrosion media was as follows: $\mathrm{PBS}<\mathrm{HSpH} 7<\mathrm{HSpH} 4<$ $\mathrm{HSCl}<$ WBS. 


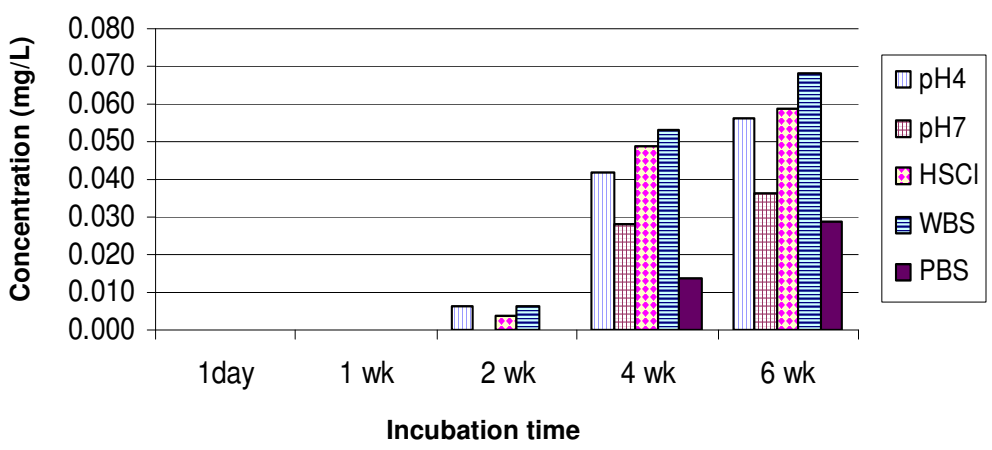

Figure 3a. Manganese ions released by new arc bar into bio-fluids.

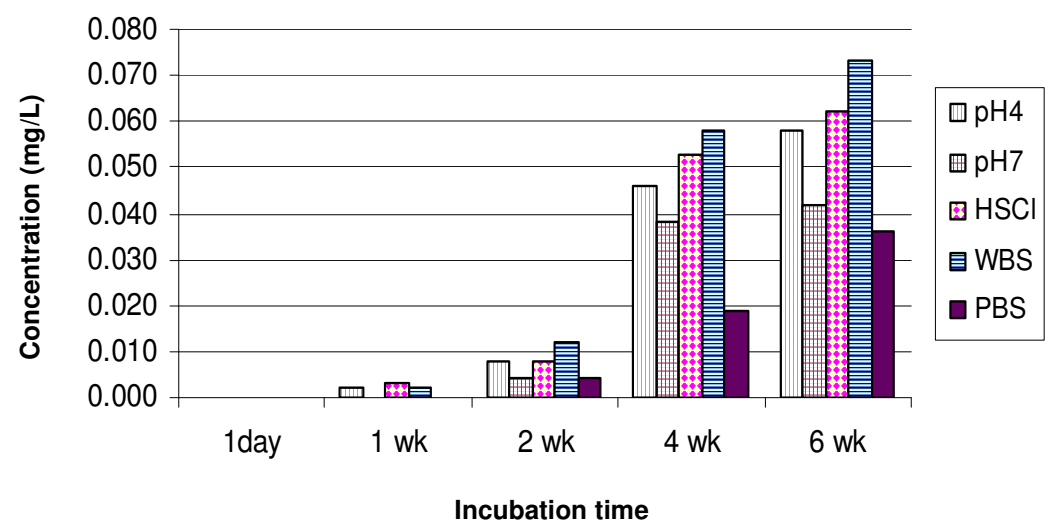

Figure 3b. Manganese ions released by reused arc bar into bio-fluids.

Release of Ni ions

The reused wires released more Ni ions than the new ones at all time points. After 6 weeks of incubation, the highest level of $\mathrm{Ni}$ ions released was in $\mathrm{HSCl}$ closely followed by WBS and $\mathrm{HSpH} 4$. The concentration of $\mathrm{Ni}$ ions in $\mathrm{HSCl}$ after 6 weeks of incubation was $0.029 \pm 0.004$ $\mathrm{mg} / \mathrm{L}$ for the new and $0.038 \pm 0.002 \mathrm{mg} / \mathrm{L}$ for the reused samples (Figure 4). From DMRT, the effect of $\mathrm{pH}$ and chloride ions variations led to marked statistical significance in the amount of $\mathrm{Ni}$ ions released into the media. Increased incubation time did not result to significant release of $\mathrm{Ni}$ ions from the new arch bar into the bio-fluids. Ageing prior use of arch bars resulted to significant release of $\mathrm{Ni}$ ions into the bio-fluids, with a positive correlation in the amount of $\mathrm{Ni}$ ions released by the new and reused wires $(r=0.902)$. 


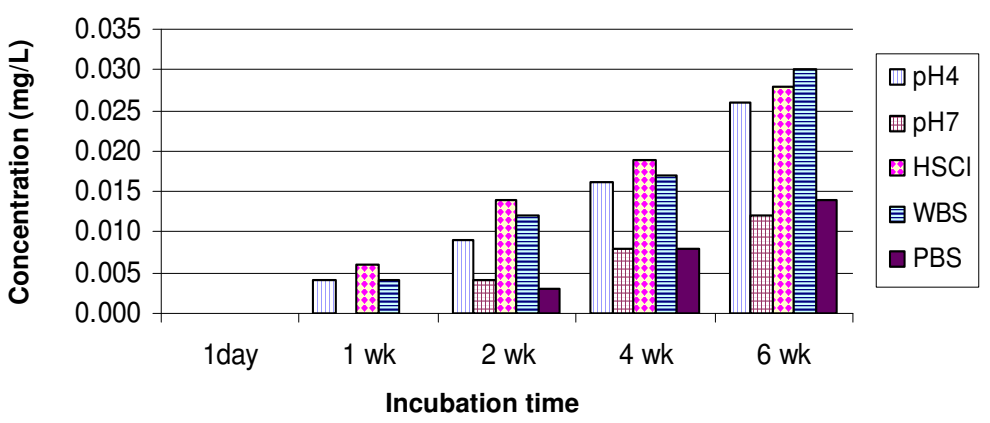

Figure 4a. Nickel ions released by new arc bar into bio-fluids.

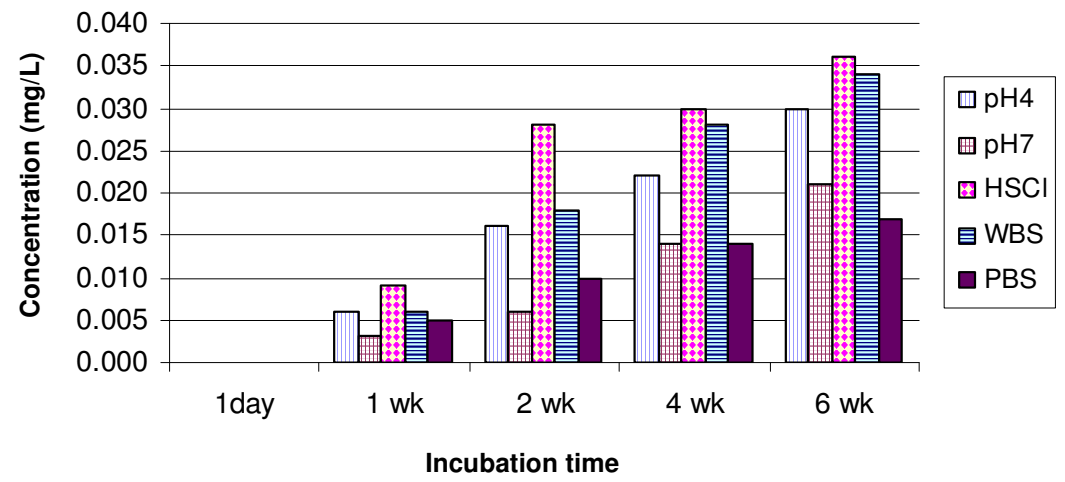

Figure $4 \mathrm{~b}$. Nickel ions released by reused arc bar into bio-fluids.

Release of Crions

Figure 5 shows that the amount of $\mathrm{Cr}$ ions released into the actual and pseudo-fluids in the study increased consistently after 1 day incubation. The reused samples released more $\mathrm{Cr}$ ions than the new ones, except after 6 week when $\mathrm{HSpH} 4, \mathrm{HSCl}$ and WBS had more of released $\mathrm{Cr}$ ions from the new wires. Chromium ions constitute about half the total concentration of metal ions released in the study. The highest amount of $\mathrm{Cr}$ ions released was recorded as $0.060 \pm 0.001$ $\mathrm{mg} / \mathrm{L}$ for the new wire incubated in $\mathrm{HSCl}$ after 6 weeks. DMRT presented a slightly significant difference in the amount of $\mathrm{Cr}$ ions released into the media by an increase in chloride ion concentration, while decrease in $\mathrm{pH}$ of the bio-fluids resulted to a highly significant difference. Increased incubation time did not result to significant release of $\mathrm{Cr}$ ions from the new arch bar into the bio-fluids. There was no significant difference between the amount of $\mathrm{Cr}$ ions released by the new and reused samples. 


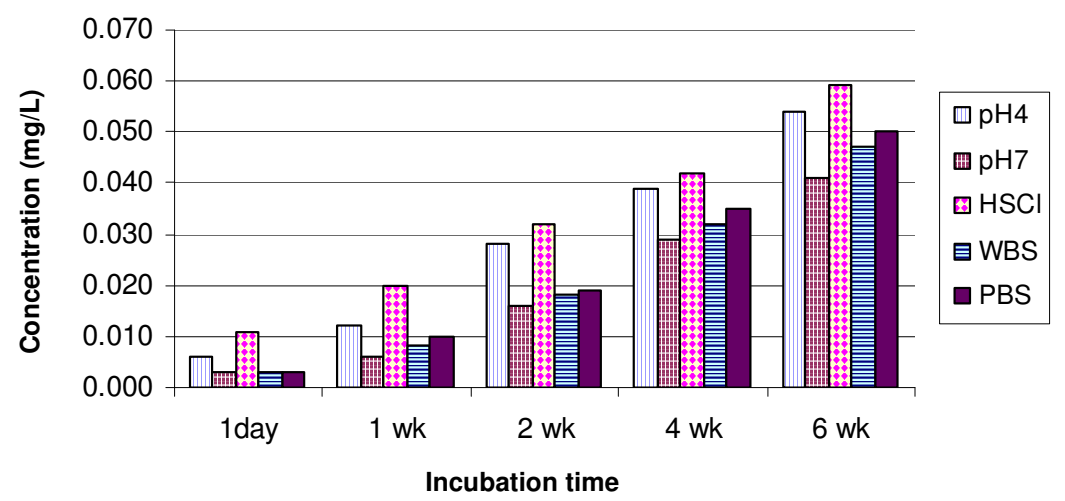

Figure 5a. Chromium ions released by new arc bar into bio-fluids.

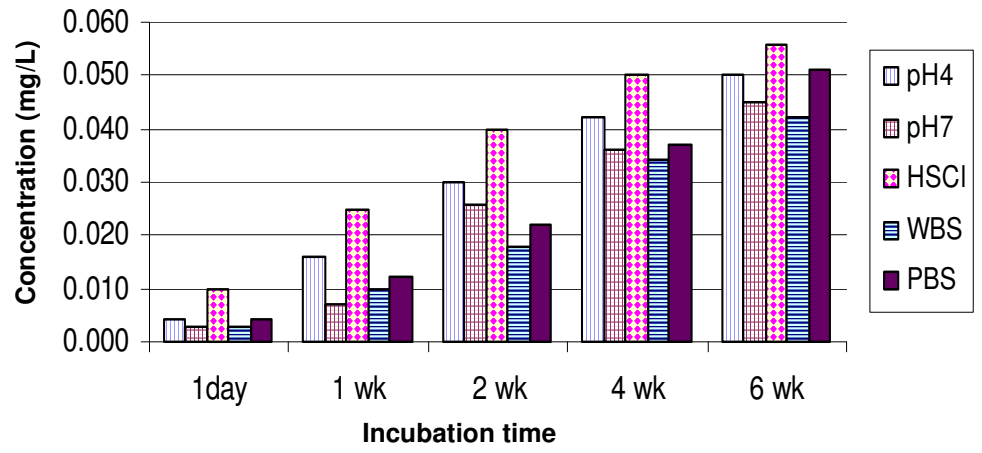

Figure 5b. Chromium ions released by reused arc bar into bio-fluids.

In the Figures ( 1 to 5 ) above, each column and bar represents the mean \pm standard deviation of three replicates. The means and standard deviations were calculated by one-way analysis of variance, with statistical difference at $\mathrm{P}<0.05$.

\section{CONCLUSIONS}

The study reports low level of released metal ions from arch bar into the various bio-fluids, with the major corrosion products being $\mathrm{Ni}, \mathrm{Fe}$ and $\mathrm{Cr}$ ions. Generally, the reused wires released more ions than the new ones, the only exception was for $\mathrm{Cr}$ at 6 weeks of incubation, with more amount of released $\mathrm{Cr}$ ions from the new wires into $\mathrm{HSpH} 4, \mathrm{HSCl}$ and WBS. The variation of $\mathrm{pH}$ and chloride ions of the bio-fluids had a significant effect on the amount of $\mathrm{Ni}, \mathrm{Mn}$ and $\mathrm{Cr}$ ions released from the wires. Increased incubation time did not result to significant leaching of corrosion products from the new arch bar into the bio-fluids. On the other hand, ageing prior use of arch bars resulted to significant release of $\mathrm{Ni}$ ions into the bio-fluids.

The present corrosion study was investigated in a static condition. The situation in the oral cavity is dynamic and might result in other types of corrosion, for example fretting, which might further enhance the release of ions from the appliance [12]. Despite the recorded levels of 
released metal ions investigated in this study, there is no great health concern, since the released amounts are significantly below the average dietary intake. It is evident that retrieved orthodontic appliances are coated by intraorally formed proteinaceous biofilm that mask the surface. Immersion of nitinol wire in Hank's solution for ten days led to decrease in Ni ions released as a result of the growth of a calcium phosphate layer on the top of the metal oxide layer [13]. By extrapolating the information from this study to in vivo conditions, the bioavailable potentially harmful constituents of stainless steel arch bar used in this study is anticipated to be negligible. Elevated levels of the metal ions may be traced to steam autoclaving of the new and reused samples, thus, the sterilisation effects may have altered the surface profile and ionic release. Soldering on SS prosthesis may result to galvanic coupling, leading to elevated release of metal ions from restorations. Also taking into account the fact that, in body conditions implant corrosion products are disseminated and eventually eliminated. The result that SS arch bar used in orthodontic appliances corrode in bio-fluids over an extended time interval is of great clinical significance in evaluating their bio-compatibility, the levels of metal ions released into the various bio-fluids is negligible. The reuse of stainless steel arch wires may pose a slightly increased risk of a reaction to host, especially nickel sensitive patients, this increased risk must be balanced against the benefit (cost savings, availability) that used arch wires give and should not be dismissed.

\section{AKNOWLEDGEMENTS}

The authors gratefully acknowledge the contributions and technical support of Dr. Omisakin O. Oluleke of the Maxillofacial and Dental Department, Ahmadu Bello University Teaching Hospital, Shika, Nigeria and Mac Arthur Foundation for financial aid.

\section{REFERENCES}

1. Chang, E.W. Mandible Fractures, General Principles and Occlusion, Columbia University Medical Centre. E-med. 2005, 1; <http://www.emedicine.com/ent/topic170.htm> accessed on January 15, 2007.

2. Tsui, H.H.; Shinn, J.D.; Yan, M.; Chia, T.K. Europ. J. Orthodont. 2004, 26, 171.

3. John, N.A. Applied Dental Material, 5th ed., Blackwell Scientific Publications: Oxford, England; 1976; pp 148-150.

4. Guyuron, B.; Lasa, C.I. Plast. Reconstruct. Surg. 1992, 89, 540.

5. Theodore, E.; Athanasiou, E.A. The Angle Orthodont. 2002, 72, 222.

6. Grimsdottir, M.R.; Gjerdet, N.R.; Hensten, P.A. Amer. J. Orthodont. Dentofac. Orthopaed. 1992, 101, 525.

7. Pereira, M.C.; Pereira, M.L.; Sousa, J.P. Biomater. 1999, 20, 2193.

8. Wenyi, J.; Mark, W.B.; Richard, A.R.; Thomas, M.P.; Donald, M.C.; Constance, R.M.; Strom, E.A.; Melvin, F.J. Biomed. Mater. Res. Appl. Biomat. 1999, 48, 488.

9. Angela, A.; Jinny, H.; Mauro, H.; Anna, P.; David, S.H.; Carmelita, G.F.J. Biomedic. Mater. Res. 2005, 79A, 512.

10. Edie, J.W.; Andreasen, G.F.; Zaytoun, M.P. Ang Orthodont. 1981, 51, 319.

11. Kirkbright, G.F.; Smith, A.M.; West, T.S. Analyst 1966, 91, 700.

12. Magnusson, B.; Bergman, M.; Bergman, B.; Soremark, R. Scand. J. Dent. Res. 1982, 90, 163.

13. Wever, D.; Velderhuizen, J.; de Vries, J.; Busscher, H.; Uges, D.; Van Horn, J.R. Biomat. 1998, 19, 761.

14. Lori, J.A.; Hanawa, T. Corr. Sc. 2001, 43, 2111. 